\title{
الإختلاط في التعليم وانعاكسه السلبي على العملية التربوية
}

\section{(The Problems of Co-Education and Its Way-out)}

\author{
* محمد انوار الكبير. \\ تلخيص المقال: إن الإسلام منهاج شامل قويم في تربية النفوس وتنشئة الأجيال ـ وتكوين الأمم وبناء \\ الحضارات. وإرساء قواعد المجد. وكرم الفرد كرامة رائعة سواء كان ذكرا أو أنثى ـ لقد أجمع العلماء والفقهاء

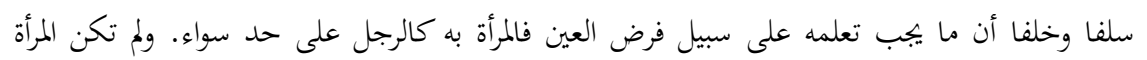

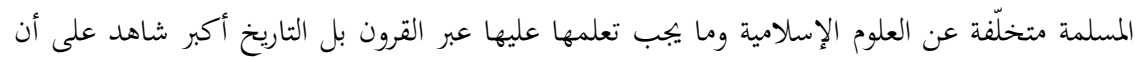

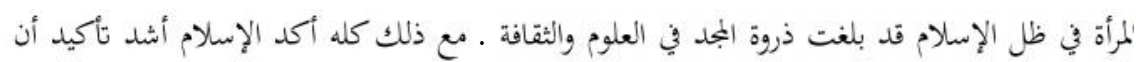 \\ كون هذا التعلم مع بقاء عفتها وحجابها وبمنأى عن اختلاط الأجانب. وقد ذهب إليه علماء الإسلام \\ وفقهائهم كما تراه في قول الإمام القابسي وابن سحنون أن تعلم المرأة يكون بمعزل عن الذكور. حتى لا لا \\ ينهتك عرضها ويسلَم شرفها مع النهي عن السفور والتبرج حفاظا وصيانة للمرأة المسلمة من عن الفتنة

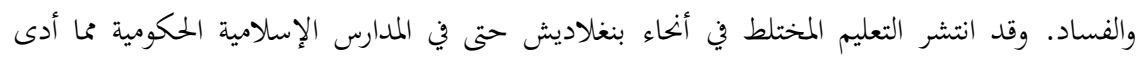 \\ الفضائح الجنسية في كل مكان. والتعليم المختلط مشغل للفتيان والفتيات عن الدراسة الفعالة والتحصيل \\ العلمي والابتكار. لأن الشهوات التي أغرقوا فيها أفسدت لياقتهم الطيبة والنفسية ـ ومن واجب المسؤولين \\ أن يهتموا بالرقابة عليهما وإنقاذها من الدمار والفساد ـ وذلك عن طريق الأسرة المسلمة و المؤسسات

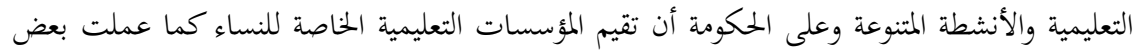

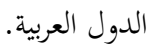 \\ الكلمات المفتاحية : الإسلام، إنسان، المرأة المسلمة، المؤسسة، الفطرة،
}

[Abstract: Islam provides a comprehensive guideline to educate the humankinds, to cultivate a generation, to build a nation and civilization. It also bestows dignity for the whole mankind men and women alike. All Islamic scholars agree that there is no difference between man and woman when it comes to acquiring knowledge as a religious obligation. Muslim

*Dr. Md. Anwarul Kabir, Associate Professor, National University, E-mail: absardu@gmail.com 
women had made tremendous headway in the realm of education and culture under the shadow of Islam throughout the history. However, Islam puts considerable emphasis on the importance of women's modesty and on the prevention of free mixing. The idea has been reinforced by the scholars of Islam such as Imam Al-Qabisi and Ibn Sahnun. They contend that in order to maintain women's dignity and honor and to prevent extramarital affairs, female education should be segregated from male.]

إن الإسلام هو منهاج شامل قويم في تربية النفوس وتنشئة الأجيال ـ وتكوين الأمم وبناء الحضارات. وإرساء قواعد المجد للمسلمين. وكرم الفرد كرامة رائعة سواء كان ذكرا أو أنثى . لقد أجمع العلماء والفقهاء سلفا وخلفا أن ما يجب تهبي تعلمه على سبيل فرض العين فالمرأة به كالرجل على حد سواء. ولم تكن المرأة المسلمة متخلّفة عن العلوم الإسلامية وما ولماء يجب تعلمها عليها عبر القرون بل التاريخ أكبر شاهد على أن المرأة في ظل الإسلام قد بلغت ذروة البمد في العلوم

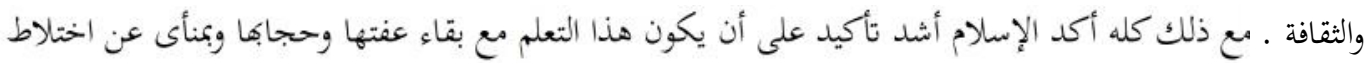
الأجانب. وقد ذهب إليه علماء الإسلام وفقهائهم كما تراه في قول الإمام القابسي وابن سحنون أن تعلم المرأة يكون بمعزل عن الذكور. حتى لا ينهتك عرضها ويسلَم شرفها مع النهي عن السفور والتبرج حفاظا وصيانة للمرأة المسلمة من الفتنة والفساد. وقد انتشر التعليم المختلط في أنحاء بنغلاديش حتى في المدارس الإسلامية الحكومية مما أدى ذلك إلى الفضائح الجنسية في كل مكان. والتعليم المختلط مشغل للفتيان والفتيات عن الدراسة الفعالة والتحصيل العلمي والابتكار. لأن الشهوات التي أغرقوا فيها أفسدت لياقتهم الطبيعية والعقلية ـ ومن واجب المسؤولين أن يهتموا بالرقابة

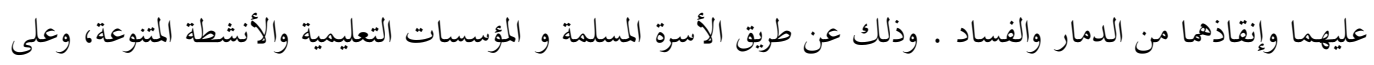
الحكومة أن تقيم المؤسسات التعليمية الخاصة للنساء كما عملت بعض الدول الإسلامية و العربية.

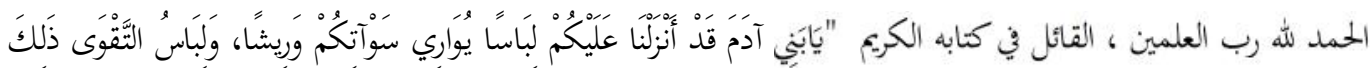

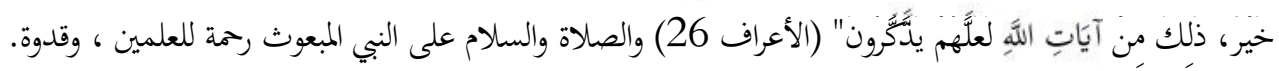
للسالكين وأسوة حسنة للإنسانية جمعاء. وعلى آله وصحبه ومن تبعهم بإحسان إلى يوم الدين. وبعد ! إن هذا الكون خلق مستهدف ـ خلقه الله لغاية مهمة ، وأن الغاية تتضح في حقيقة أن الله سخّره لخدمة الإنسان. وخلق الإنسان لغاية أهم من ذلك. كما نحن نتعرف على ذلك بقوله تعالى "وما خلقت الجن والإنس إلا ليعبدون" 
( لذريات 56) أمرهما الله بالعبادة والإطاعة له من غير فرق جنسي بينهما بصيغة "اعبدوا الله" و "أطيعوا الله و رسوله" وغيرها من الأيات القرآنية. ومن حكمة الباري جل وعلا أن تكون هذه العبادة مستمرة إلى الموت أو إلى أجل لايعلمه إلاهو. وقد جرت سنة الله فيها لبقاء هذا الكون وليصل النوع البشري إلى أجله أن خلق كل شيء زوجين اثنين كما خلق الإنسا ن في ذكر وأنثى. وأودع فيهما الميول الفطرية والغزائر الكامنة في خلقتهما لحفظ النسل ولأداء المهمة الإلهية في الأرض إلى قيام الساعة.

وأنزل الله من التشريعات والأحكام ما يلبي حاجات هذه الميول والغرائز الجنسية وما يكفل لها الاستمرار والنماء والبقاء.

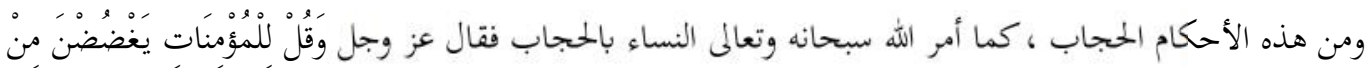

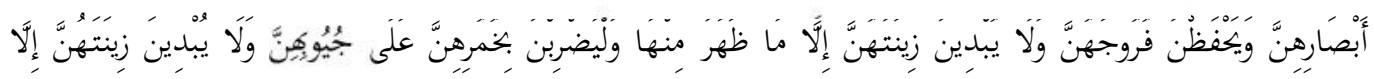

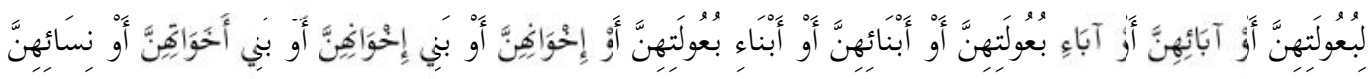

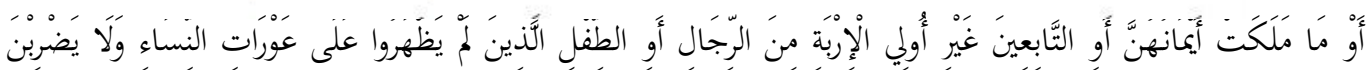

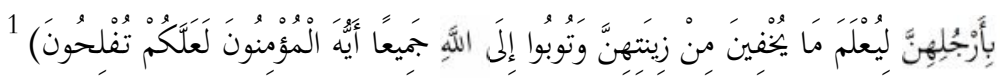
بـ المرأة أن تستر جميع بدفا وزينتها المكتسبة من الثوب وحلي ونهوها عن الرجال الأجانب ، والنهي عن كشف الستر والسفور والتبرج و الاختلاط إن الاختلاط بين الرجل والمرأة في بجالات التعليم والتوظيف يؤدي إلى الفساد ، لأنه خلاف القانون الإلهي. فمن خلال هذا البحث المتواضع نحن بصدد تحديد أخطار التعليم المختلط وبيان حلها.

\section{تعليم المرأة في الإسلام}

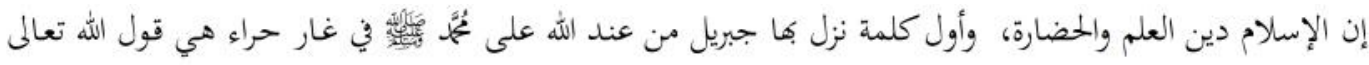

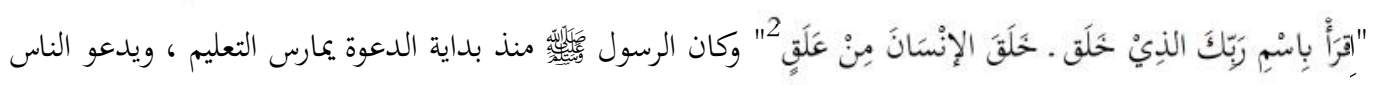

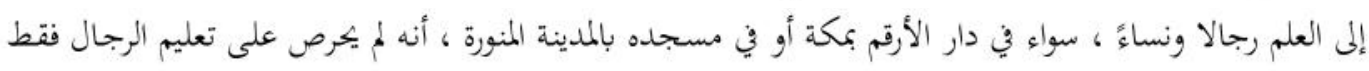
بل اهتم اهتماما شديدا بتعليم النساء أيضا. وخصص أوقاتا محددة لتعليم النساء ، وقد ثبت في الصحيحين البخاري

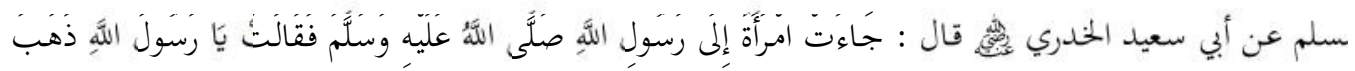

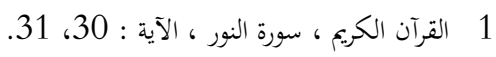

2 


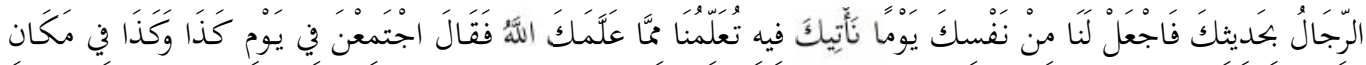

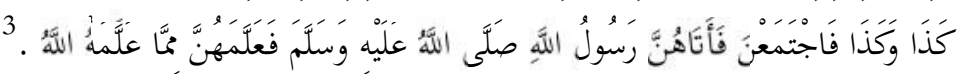

وقد جعلهما الله في بعض الأمور على مستوى واحدٍ وخاطبهما بصيغة واحدة إذ أدى أن نعرف التسوية بينهما حتى ما يتسويان في الثواب والعقاب فما يطلب من الرجل يطلب من المرأة وما يجازي به الرجل أو يعاقب بحازي به المرأة

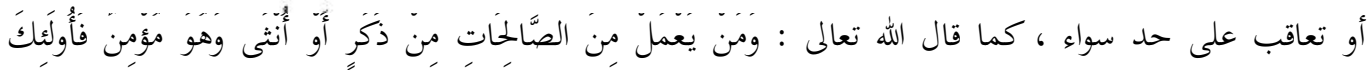

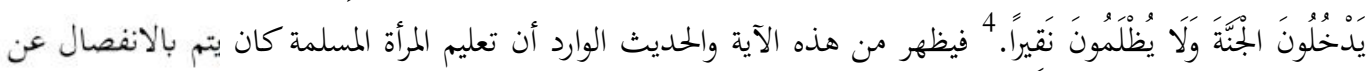

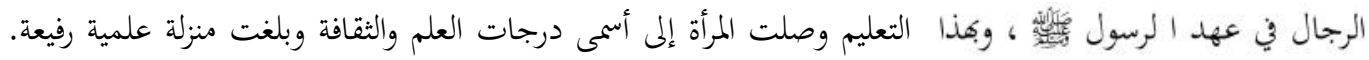
ويرى جميع الفقهاء في مقدمتهم الإمام القابسي وابن سحنون أن تعليم البنت يكون بمعزل عن الذكور ، وبمنأى عنهم حتى يسلم للبنت عرضها وشرفها. ،هذا الرأي مستمد من حكم الشرع الذي أمر النساء بالاستتار. والدليل على ذلك

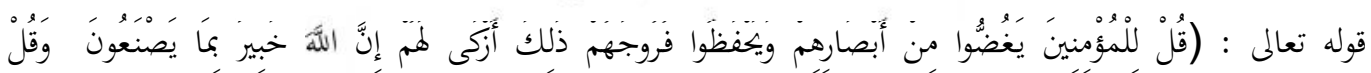

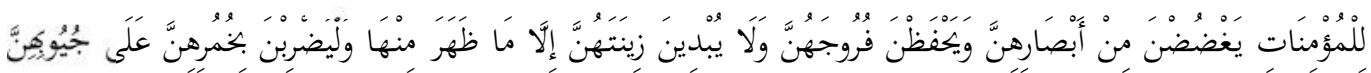

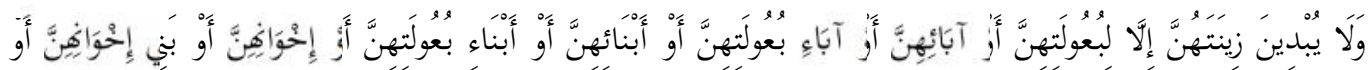

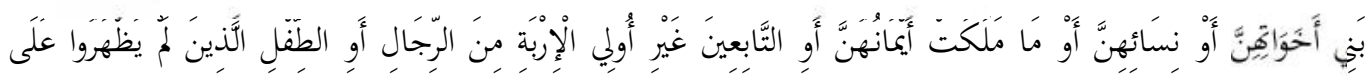

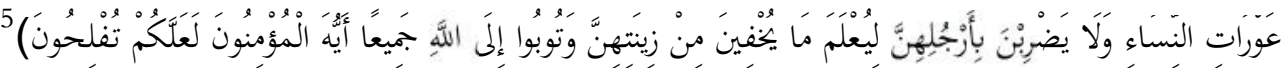
ذذه الآية توضح أن المرأة مأمورة بالستر وغض البصر، ووضع الخمار على الرأس والصدر وعدم إبداء الزينة والمفاتن ومنع الإسلام الاختلاط بين الطالب والطالبة في كل مكان وفي كل زمانٍ . والذين يدعون أن الاختلاط سبيل إلى -يب الدوافع الجنسية فإنم في الواقع يفترون على الشرع ويتجاهلون الفطرة الغريزة للإنسان، لأن النار لا تتطفئ بالاحتكاك وإن انطفأت فإن دوام الاحتكاك يجدد اشتعالها. وهم ينكرون الحس ويريدون أن يغيروا نواميس الكون وسنن

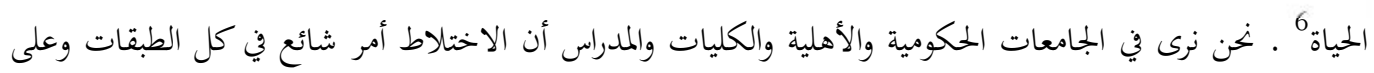

3

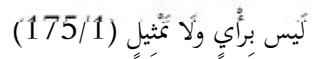
4 القرآن الكريم ، سورة النساء ، الآية ـ 124

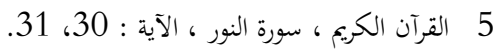

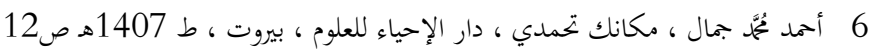




$$
818
$$

ختلف المستويات وأن الفضائح الجنسية تزداد كل يوم ـ وكثير من الطلاب بعد التخرج من الجامعات لا يرغبون في الزواج من الطالبات اللاتي درسن معهم ، لأغم رأووا حالهن واختلطوا بكن وقت الدراسة.

\section{أخطار التعليم المختلط وانعكاسه السلبي على العملية التربوية}

إن اختلاط لطلاب بالطالبات في التعليم يضر بالأخلاق، ويضر بالنفس ، ويضر بالعقل، ويضر بالدين، ويضر

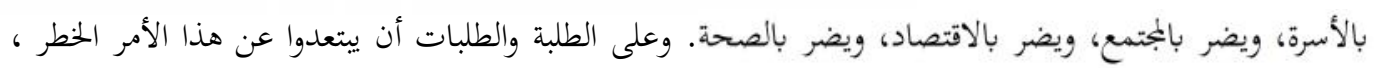
وذلك عن طريق تربية الطالب والطالبة إيمانيا وإعدادهما خلقيا.

لاشك في أن الطالب والطالبة يواجهان في وقتنا الحاضر مشكلات عديدة ، ومن أهها مشكلة الاختلاط في التعليم الذي انتشر في معظم الجامعات والكليات والمدارس الحكومية في أنحاء بنغلاديش. لأن الاختلاط يخرب عفة الرجل والمرأة ويأتي بالانحلال الخلقي، ويدمر الآداب التي اصطلح الناس عليها في المجتمع و المذاهب والأديان. وأنه يفسد هدوء المشاعر ونظافتها مما يؤدي إلى إضعاف الروابط الفطرية في الحياة الإنسانية باستبعاد قيم الأسوة وقيم الجُتمع ورقابتها بما يكطم الحواجز الخلقية أمام الفوضى الجنسية. 7 إن ترك الإنسان في القرن العشرين على مسار الفطرة في الزواج واتباع فوضى الجاهلية في الأخلاق جرع الإنسانية الشقاء والضياع. بل إنها تمد الفساد إلى كثير من البنات اللاتي تنزلق أقدامهن إلى الهاوية، استجابة لإغراء المال ، وإشباع لوطر، والتمتع باللذات العارضة التي تعقبها المصائب والآلام. ونجد الأخبار الكثيرة السيئة المخزنة للفوضى الجنسية بين الطلبة والطالبات، وبين المدرسين والطالبات التي تنشر في الجرائد في مجتمعنا المعاصر كل يوم.

لوسائل الفعالة للقضاء على الاختلاط ومحو آثاره في التعليم

إن الستر والحجاب هما أعظم عون على العفاف والحصانة. وإن احترام القيود التي شرعها الإسلام في علاقة الجنسين هو صمام الأمن من الفتنة والعار والفضحية والخزية. وإن نظرة الإسلام في كل شأن نظرة إلى أصل الفطرة والميل الجنسي

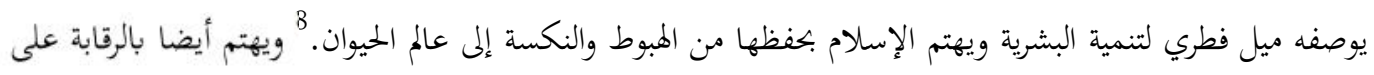

7

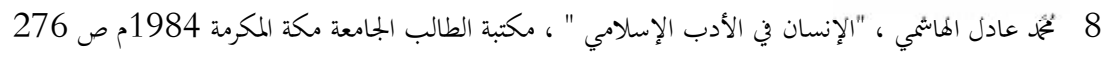


الطالب والطالبة ولأن عدم الرقابة ، والابتعاد عن الجدية العلمية والأعمال المثمرة النافعة قد يؤدي إلى مخاطر اجتماعية لا تقتصر على الأضرار بالشباب والفتيات وحدهم بل تتعدى أضرارها إلى البشرية والحياة الاجتماعية.

\section{(1) (1) ومن أهمها الأسرة المسلمة}

إن الأسرة المسلمة هي أولى المؤسسات وأولى الجماعات وأهمها وأقواها لرعاية الأطفال من ذكر وأنثى ولرعاية الفتاة خاصة. وإنها لبنة قوية في بنيان الأمة أو خلية حية في جسم المجتمع ، ومن ثم كان صلاح الأسرة هو السبيل لصلاح الشباب والفتيات ـ وكان فسادهم وانحلالهم اط فسادهم وفساد المجتمع، ومن الأسرة يستقي الطفل ما يتعلمه من ثقافة وقيم وعادات واتحاهات اجتماعية. وكل هذه الأنماط السلوكية تتعلمها الفتاة في مراحل تكوينها الأولى. ولهذا عتنى النظام الاجتماعي الإسلامي بالأسرة عناية كبيرة تظهر في الأحكام الكثيرة بشأها وذلك لإعداد الفتاة المسلمة القوية بالإيمان و القادرة على النهوض برسالتها وأداء وظائفها.

إن الزواج هو السبيل الطبيعي لتكوين الأسرة واستمرار بقاء النسل الإنساني إلى أن يرث الله الأرض ومن عليها ، وقد

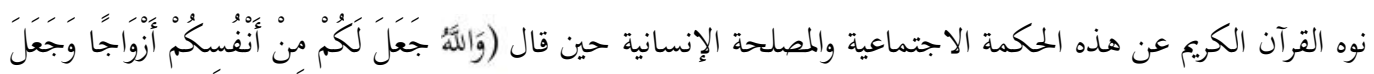

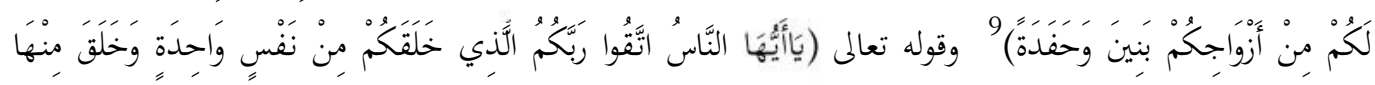

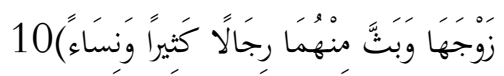

الأسرة المسلمة هي الغارسة التي تغرس في الفتاة سمو الأخلاق وحسن التربية ونور العلم والمعرفة ـ على الأم أن تفهم الفتاة أن الحجاب ليس تقييدا لحرية المرأة بل هو وقاية لما من أن تسقط في درك المهانة. ووحل الابتذال. وأن الحجاب

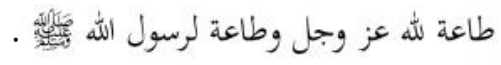

الأسرة المسلمة أن تُعِود الفتاة الحجاب الإسلامي ، لأن الفتاة في حجابها في ستر مكين و درع متين وحصن حصين وفي عز وشرف و خير وسعادة ـ وعلى الأسرة المسلمة أن تهتم بالرقابة على الفتاة ـ لأن ضعف الرقابة من الوالدين في التوجيه والإرشاد والنصح يؤدي إلى عديد من المشكلات الاجتماعية مثل التمرد على سلطة الوالدين، والانخراف عن القيم المبادئ الإسلامية وغيرها من المخاطر التي لا تقتصر على الفتاة فقط بل يتعدى أثرها إلى افراد

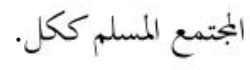

9 القرآن الكريع ، سورة النحل ، الآية 72 10 القرآن الكريم ، سورة النساء ، الآية 1 الآي 


$$
\text { الإختلاط في التعليم وانعاكسه السلبي على العملية التربوية/ د. تُحَّمَ انوار الكبير }
$$

وأن الإسلام اهتم اهتماما بالغا بإعداد الفتاة الصالحة في بناء المُتمع على أساس من الدين والفضيلة والحلق والقويم. وفي حدود الخصائص الطبيعية لكل من الجنسين ، فرفع شأها وكون شخصيتها، وقرر حريتها ، وفرض عليها طلب العلم والمعرفة ثم ناط بها من شؤون الحياة ما تميئها لها طبيعة الأنوثة وما تحسنه حتى إذا كضت بأعبائها كانت زوجة، و مربية وربة منزل، مدبرة وكانت دعامة قوية في بناء الأسرة والمجتمع، وكان من رعاية الإسلام لها حق الرعاية أن أحاط عزتما كرامتها بسياج منيع من تعاليمه الحكيمة وحماية أنوثنها الطاهرة من العبث والعدوان وباعد بينها وبين مظان الريب

$$
\text { وبواعث الافتنان عن طريق الحجاب. }
$$

تحاول الأسرة أن تغرس في قلوب الفتيات القيم والروحية والإنسانية المستمدة من الدين كعاطفة الحب للآخرين واحترام حقوق الوالدين وأفراد الأسرة والجيران وغيرها من الأقرباء والصديقات والزميلات ومصالحهم، والإخلاص والأمانة والوفاء بالعهود والمواثيق والصدق في القول والعمل وعزة النفس وتقدير المسئولية نحو ربها وخو نفسها وأسرتحا وبجتمعها ووطنها وأمتها والحرص على تأديتها على خير وجه. وتبعد عن الا ختلاط والتبرج.

(2) (2) (المؤسسة التعليمية

إن المؤسسات التعليمية مثل المدرسة والكلية والجامعة فهي تستطيع أن تلعب دورا هاما في رعاية الفتاة وإعدادها روحيا

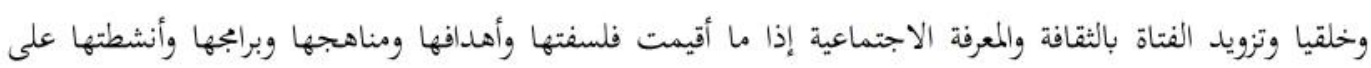
أساس من الدين والأخلاق.

والواجب على المؤسسات التعليمية مثل المدرسة الإسلامية وال لية والجامعة أن تميئ للبنات التعليم الخاص بهن دون اختلاط. وأن تنظم لهن البرامج الدراسية الخاصة التي تتناسب مع وضعهن وطبيعتهن وحاجتهن، وتمنع اختلاط الطلاب ن في حقل التعليم ولا فرق بين الابتدائي والمتوسط والثانوي، والجامعي ـ لأن الإسلام منع الاختلاط بين الرجال والنساء في جميع الأمور .لأنه عين الفساد. وعلى الحكومة أيضًا أن تقيم المؤسسات التعليمية الخاصة للنساء كما عملت المملكة العربية السعودية والكويت والإمارات العربية المتحدة وغيرها من الدول العربية .

والمؤسسات التعليمة ليس واجبها تدريس مواد دراسية فقط وإنما واجبها امداد للأسرة حيث أها تمتم فيها بجميع العلوم والفنون المفيدة للحياة والجمتمع الإسلامي وعليها أن تتم أيضا في مناهجها بتراثنا الإسلامي وبالتربية الدينية التي تبين للطالبات أصول الحياة الاجتماعية وتعاليم الدين وأحكام الشريعة المناسبة. 
ومن الضروري المؤسسة التعليمية بحل مشاكل الفتاة النفسية والاجتماعية الناجمة من الثطور التكنولجي إستخدام وسائل الإعلام المرئية والمسموعة والمطبوعة التي من شأخها بلبلة أفكار وخلخلة ثوابتها. فعلى المؤسسات تعليمية أن تعالج تلك المشاكل بالبرامج الثقافية والكتب المعدة لها والنشاطات المتنوعة مما يساعد في بناء الفتاة بناء سليما متكاملا إيجابيا يقلل كثيرا من هذه الأخطار.

من الضروري أيضا أن تهتم المؤسسات بإبقاظ حس الفتاة وتثقيفهن بثقافات حديثة حتى تشعر بتلك المخططات التي تصممها الشيوعية والماسونية اليهودية والدوائر الاستعمارية والفئات العملية الخائنة للأمة الإسلامية. والتي تعمل لإبعاد الفتاة عن القرآن الكريم وعن تعاليم الإسلام. وإخراجها عن عقيدها وخلقها وكرامتها وتدعو إلى تعليمها وفق مناهجهم بة الخبيثة لتصبح متحررة من الإسلام وتهتم بتخريج جيل من الفتيات المسلمات اللواتي لا يعرفن عن دينهن وتاريخهن شيئًا. تعلقن تعلقا كاملا بالحياة الغربية التي تتيح لهن أن ينطلقن باسم التحرر والمساواة في تيار الفساد

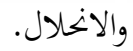

سسات التعليمية الفتاة بالقدر الأساسي من المعارف والاتحاهات والمهارات وتنمي شخصيتها من خلال اكتشاف قدراتما ومواهبها، وتوجيهها دراسيا ومنهجيا وفقا لاستعداداتما وقدراتها الخاصة لتحمل المسؤليات المعطاة على عاتقها.

\section{(3) البرابج الدينية}

يمكن ان تساهم المعلمات وأساتذات الجامعات ذات الخببرة والاختصاص في وضع برامج للتوجيه والدعوة والإرشاد للفتاة المسلمة وتساعدها على مواجهة المشكلات الحيوية المحلية، زتدربها على اتخاذ القرارات وتحمل المسؤوليات ، يتم ذلك عن طريق برامج دينية ويرامج للتوجيه النفسي والإرشادي والتربوي، وبحيث تعقد هذه البرامج داخل المدارس أو الجامعات أو قاعات المحاضرات أو في معسكرات ومخيمات للتوجيه الجماعي. بالمناقشات الجماعية لتدارس القضايا والمشكلات التي تواجهها الفتاة، وتبين وسائل المواجهة المنطقية والموضوعية كما تعمل هذه البرامج على تحقيق التوازن بين إشباع الحاجات الإنسانية وتحقيق الذات مع القدرة على الضبط والالتزام بما يتفق مع الشريعة الإسلامية. هذا و إن تتضمن البرامج أيضا ما يواجه الفتاة من العوئق والمشكلات من خلال الأنشطة العقلية والعملية التي تطرح أمامها ـ بما ينمي طاقاتما العقلية لتصبح قادرة على ضبط النفس وكبح شهواتما ونزواتها لمواجهة مغريات الحياة العصرية والتبصر والتدبر والتغلب على العقبات عند مواجهتها الأفكار الشاذة التي تنافي العقيدة السمحة. 


$$
\text { الإختلاط في التعليم وانعاكسه السلبي على العملية التربوية/ د. تُحَّمَ انوار الكبير }
$$

إن الأنشطة الترويحية الحرة في أوقات الفراغ مهمة للفتاة المسلمة لأن ممارسة النشاطات الحرة البناءة في وقت الفراغ مهم لصحة الفرد وكيانه ، وهي تساعد الفتاة في اكتساب الخبرات والمهارات والأنماط المعرفية وتنمية الذوق الحسي السليم، وتهيئة فرص الإبداع والابتكار. مجالات الأنشطة في أوقات الفراغ كثيرة منها : (1) النشاط الابتكاري "الحرَف اليدوية، والديكوري، الزخرفة، الرسم، الكتابة، فلاحة البساتين، الطهو ،

$$
\text { التفصيل، تنسيق الورود، والنسيج، الخزف. }
$$

$$
\text { (2) - جمع الفتنيات : الكتب واللوحات الفنية، الخرائط الجغرافية. }
$$

(3) الأنشطة التربوية التعليمية : عالم الحيوان ، عالم النبات، عالم النحل، عالم الطيور، قراءة القصص و كتب السيرة ، التاريخ الإسلامي، أحسن القصص والروايات العالمية، العالم الإسلامي والعربي وغيرها من الأنشطة. وبهذه الأنشطة المختلفة المتنوعة تستطيع الفتاة أن تقضي أوقات الفراغ فيما يعود عليها وعلى مجتمعها بالفائدة.

\section{الخايتمة}

إن تعليم المرأة المسلمة ضروري وشجع الإسلام على تعليمها وتعلمها. لأفا مسؤولة عن تحمل أعباء الحياة ومكلفة بالشرع ، ولكن تعليمها يكون بمعزل عن الذكور وبمنأى عنهم حتى يسلم عرضها وشرفها، وأخها مأمورة من الله بالستر وغض البصر ووضع الخمار على الرأس وعدم إبداء الزينة والمفاتن، ومنع الإسلام الاختلاط بين الطالب والطالبة ، لأنه يحرك في النفس كوامن الغريرة ويشعل نار الشهوات الجامحة ويؤجج عواطف الغرام والحب ويغري كلا الجنسين فيرخي

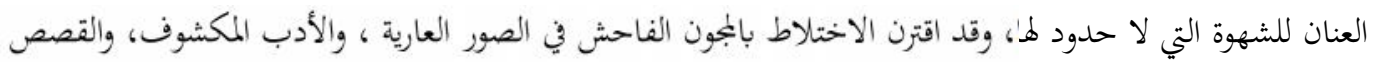
الغرامية، وحفلات الرقص المثيرة، وينشأ الناشئة في هذا الجو المحموم الذي تغلي مراحل بجتمعه بالأغاني الماجنة، وصور الإغراء الفاحشة فتسيطر عليهم هذه النزعة والاستثارة الجنسية التي تطفي فيهم القوى الفكرية والعقلية. ه المسؤولين أن يهتموا بالرقابة عليهن وتكون الرقابة عن طريق الأسرة المسلمة، والمؤسسات التعليمية والبرامج الدينية. تحاول هذه المؤسسات أن تغرس في قلوب الطالبات القيم الروحية والإنسانية المستمدة من الدين. وعلى ككومة أن قيء للبنات التعليم الخاص بهن دون الاختلاط وتنظم البرامج الدراسية التي تتناسب مع وضعهن وتلبي حاجتهن وتمنع اختلاط الطلاب بكن في حفل التعليه. 


$$
\begin{aligned}
& \text { المراجع والمصادر }
\end{aligned}
$$

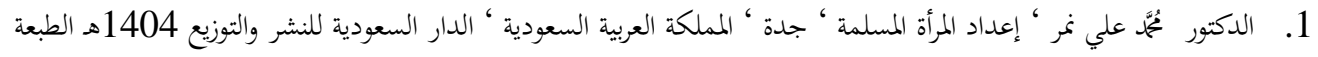

$$
\begin{aligned}
& \text { الثالثة . الصفحة } 106 \text {. }
\end{aligned}
$$

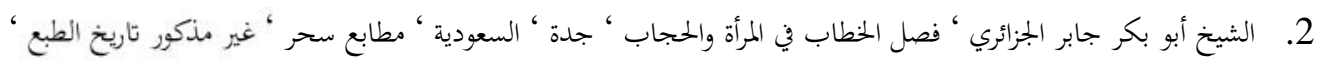

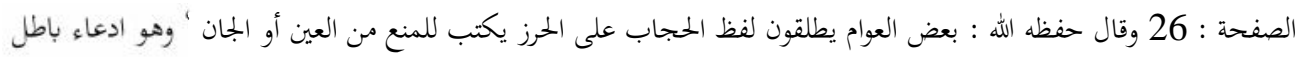

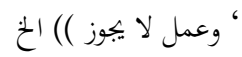

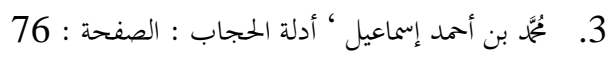

$$
\begin{aligned}
& \text { 4. القرآن الكريم ، سورة النور ، الآية : 30، } 31 . \\
& \text { 5. القرآن الكريم ، سورة العلق ، الآية 1-2 }
\end{aligned}
$$

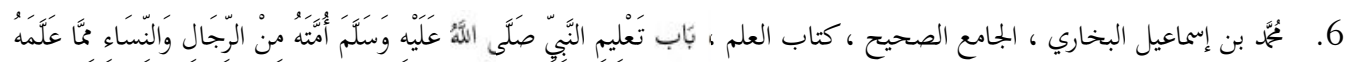

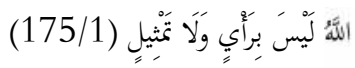

$$
\begin{aligned}
& \text { 7. القرآن الكريم ، سورة النساء ، الآية ـ } 124 \\
& \text { 8. القرآن الكريم ، سورة النور ، الآية : 30، } 31 . \\
& \text { 9. أمد يُّة جمال ، مكانك تحمدي ، دار الإحياء للعلوم ، بيروت ، ط 1407هـ ص12 } \\
& \text { 10. عبد الله ناصح علول ، "تربية الأولاد في الإسلام" ج } 1 \text { دار السلام للطباعة جدة ص } 277 \\
& \text { 11. تُحّمّ عادل الهاشي ، "الإنسان في الأدب الإسلامي " ، مكتبة الطالب الجامعة مكة المكرمة 1984م ص } 276 \\
& \text { 12. القرآن الكريم ، سورة النحل ، الآية } 72 \\
& \text { 13. القرآن الكريع ، سورة النساء ، الآية } 1
\end{aligned}
$$

